\title{
Clinical radiographic outcomes and survivorship of medial pivot design total knee arthroplasty: a systematic review of the literature
}

\author{
Mattia Alessio-Mazzola ${ }^{1,2}$ (D) Antonio Clemente ${ }^{1,2} \cdot$ Antonio Russo $^{1,2} \cdot$ Peter Mertens $^{3} \cdot$ Giorgio Burastero $^{4}$. \\ Matteo Formica ${ }^{1,2} \cdot$ Lamberto Felli $^{5}$
}

Received: 1 December 2020 / Accepted: 29 September 2021 / Published online: 11 October 2021

(c) The Author(s) 2021

\begin{abstract}
Background Total knee arthroplasty is a reliable procedure able to reduce pain and disability in patients suffering from osteoarthritis. However, a considerable percentage of patients still experiences unsatisfactory results. Medial pivot total knee arthroplasty has been introduced in the clinical practice to overcome problems related with classic design implants and better mimic native knee kinematics. The aim of this study was to analyze survivorship and clinical and radiographic outcomes of medial pivot implants.

Methods A systematic research was conducted in eight different databases. Thirty-four studies met the inclusion criteria and were included in the analysis. Data on objective and patients-reported outcomes, radiographic alignment, and survivorship were collected and analyzed. Revision rate was expressed as revision per 100 components years.

Result A total of 3377 procedures were included. Mean follow-up was 85.7 months (range, 12-182). The revision per 100 components years was 0.19 , which corresponds to a revision rate of $1.9 \%$ after 10 years. Mean post-operative range of motion was $117.3 \pm 0.4^{\circ}$. Mean clinical and functional Knee Society Score were, respectively, $85.9 \pm 1.1$ and $84.7 \pm 3.5$ at final follow-up. Post-operative femorotibial alignment was $177.1 \pm 0.5^{\circ}$. Alfa and beta angles were $95.7 \pm 0.1^{\circ}$ and $89.2 \pm 0.1^{\circ}$, respectively. Gamma and delta angles were $2.3 \pm 0.6^{\circ}$ and $86.7 \pm 0.4^{\circ}$.

Conclusion Medial pivoting implants provided excellent survivorship and low revision rate, as well as good-to-excellent results in term of objective and patient-reported clinical outcomes, and reliable correction of radiographic parameters. More high-quality studies with long-term follow-up are needed to clarify the role of medial pivoting implants.
\end{abstract}

Keywords Medial pivot knee $\cdot$ Medial pivot TKA $\cdot$ Medial congruent knee $\cdot$ Medial stabilized knee $\cdot$ TKA design $\cdot$ TKA kinematics

Mattia Alessio-Mazzola

mattia.alessio@hotmail.com

1 Orthopedic Clinic, Ospedale Policlinico San Martino, Largo R. Benzi 10, 16132 Genoa, Italy

2 Department of Surgical Sciences and Integrated Diagnostic (DISC), University of Genoa, Viale Benedetto XV 6, 16132 Genoa, Italy

3 Orthopaedics and Traumatology Department, ZNA Middelheim, Antwerp, Belgium

4 Centro di Chirurgia Protesica, Istituto Ortopedico Galeazzi IRCCS, Via Riccardo Galeazzi 4, 20161 Milan, Italy

5 Istituto Ortopedico Galeazzi IRCCS Chirurgia Articolare Sostitutiva e Chirurgia Ortopedica, Via Riccardo Galeazzi 4, 20161 Milan, Italy

\section{Introduction}

Total knee arthroplasty (TKA) represents a safe and reliable procedure to reduce pain and functional limitation caused by end-stage osteoarthritis (OA) [1]. The incidence of primary TKA is $450 / 100,000$ and annual rates of surgical procedures are widely increasing worldwide [2-4].

Despite the continuous studies to develop new prosthetic designs with advanced kinematic concepts, unsatisfactory results are still reported in $20 \%$ of patients undergone TKA [5]. The importance of a reliable prosthetic design together with surgical and medical strategies has been emphasized to improve the functional outcome and achieve better clinical results in TKA [6].

Native kinematic of the medial compartment of the knee is a "ball-and-socket" mechanism, with medial femoral 
condyle constrained in a pivot motion, while the lateral femur is free to translate posteriorly through a complete arc of flexion [7].

The medial pivot design was introduced in $1994 \mathrm{mim}-$ ing the physiological knee kinematic, to ensure greater efficacy of extensor mechanism in full range of motion (ROM) $[8,9]$. This philosophy is based on femoral component with single- or multi-radius curve and a tibial insert with a highly congruent medial compartment and flat lateral compartment. The anteroposterior stability is ensured by a raised anterior lip of polyethylene with minimum risk of condylar lift off $[9,10]$.

Several studies showed promising mid-term results of medial pivot TKA [11], but the long-term survivorship and clinical outcome have not been extensively investigated with high level of evidence.
The purpose of this systematic review is to analyze survivorship and clinical and radiographic outcomes of medial pivot design TKA.

\section{Material and methods}

\section{Literature search and inclusion criteria}

A systematic review of the literature has been performed, following Cochrane Handbook of Systematic Reviews of Interventions [12] and Preferred Reporting Items for a Systematic Reviews and Meta-Analyses (PRISMA) [13] for study selection (Fig. 1).

A systematic search from January 1st, 1990, until October 1st, 2020, was performed in the following databases: the Cochrane Central Register of Controlled Trials (CENTRAL), MEDLINE/PubMed, Embase, Scopus, the Science
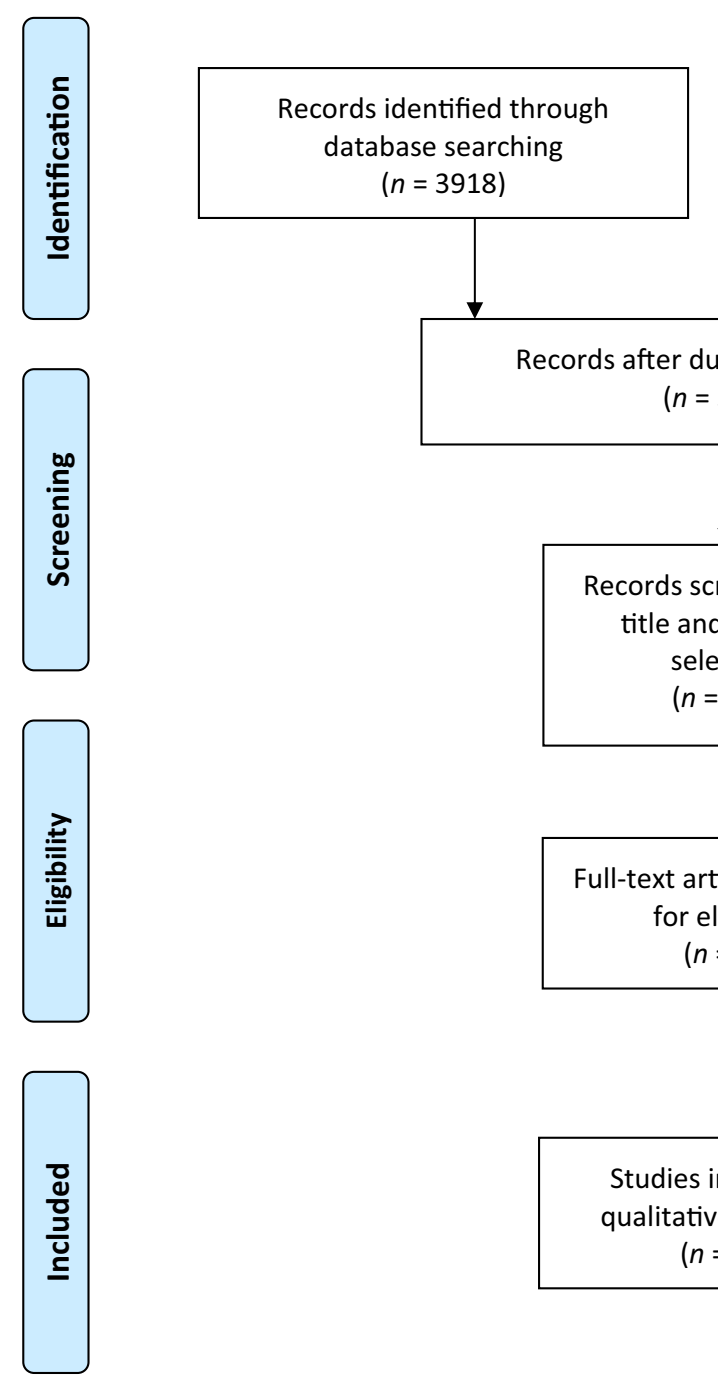

Additional records identified through other sources $(n=3918)$

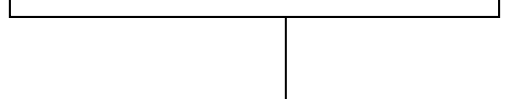
$(n=5)$

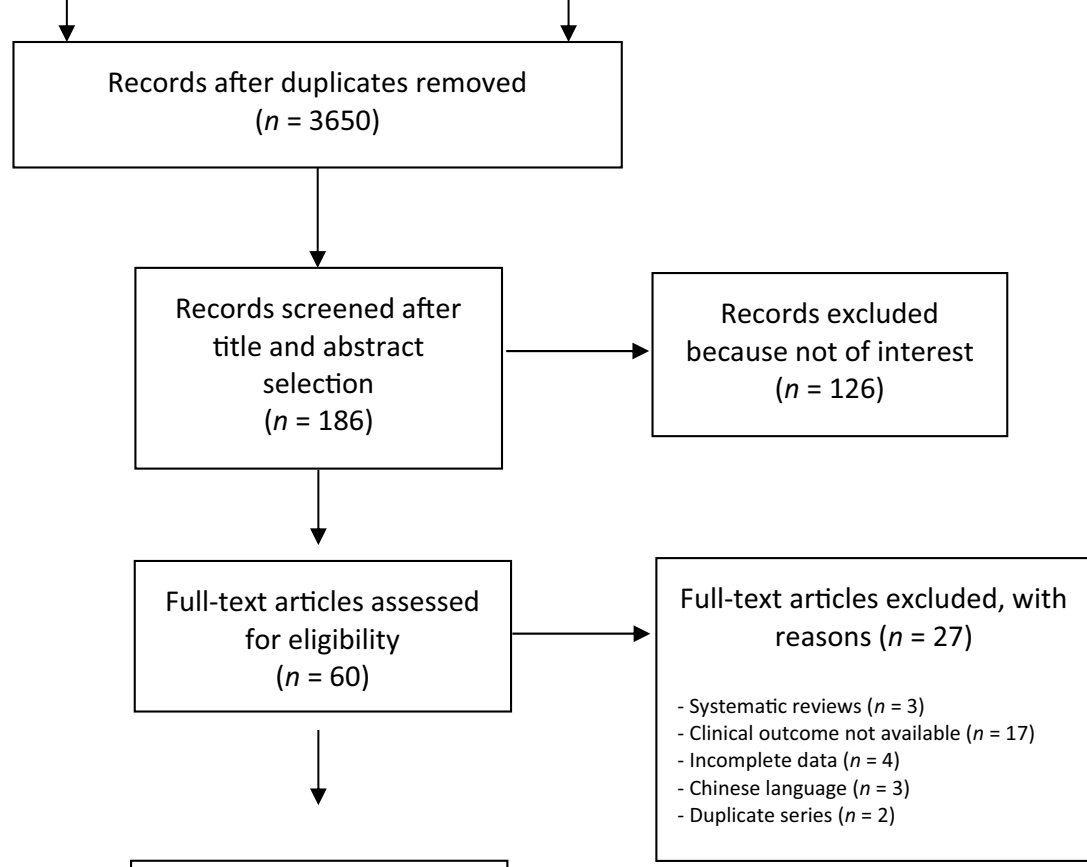

Studies included in

qualitative synthesis ( $n=31)$

Fig. 1 PRISMA flow diagram 
Citation Index Expanded from Web of Science, ScienceDirect, CINAHL, and LILACS. The research was conducted using the following keywords alone and in all the various combinations: "Medial pivot knee", "TKA design", "medial congruent knee", and "medial stabilized knee".

Clinical studies reporting objective and patient-reported outcome of medial pivot design TKA were considered eligible for inclusion. There was no quality restriction for study inclusion. Case report, technical notes, editorial commentaries, ex vivo, biomechanical, pre-clinical, and clinical studies without adequate quantitative or qualitative data were excluded. Studies that did not report clear clinical-functional data or survivorship of primary medial pivot TKA were excluded from this research.

Two reviewers independently screened each title and abstract collected from the primary electronic search. In case of relevant title and abstract, the full-text version was obtained.

All references of each study were screened to find any additional relevant paper potentially missed with the first review process. The two reviewers independently followed the same checklist to screen all studies and evaluate the eligibility criteria. Disagreements were resolved through discussion with third reviewer.

The primary endpoints of this analysis were the survivorship and clinical outcome of medial pivot design TKA and revision rate. Secondary endpoints were radiological alignment and complications.

\section{Appraisal of studies' quality and risk of bias}

The level of evidence of included studies were evaluated through the adjusted Oxford Centre For Evidence-Based Medicine 2011 Levels of Evidence [14]. The quality of the studies was defined using the Grading of Recommendations Assessment, Development, and Evaluation (GRADE) system [15], rating quality of evidence in systematic reviews. After the evidence is collected and summarized, the GRADE system provides explicit criteria for rating the quality of evidence that include study design, risk of bias, imprecision, inconsistency, indirectness, and magnitude of effect.

The risk of bias was assessed with "Risk Of Bias" (Rob 2.0) for Randomized Trial (RCT) and "Risk of bias in nonrandomized studies" (ROBINS-I) [16] to evaluate non-RCT studies.

Relevant conflict of interest having potential impact on study design and results were considered and reported.

\section{Data extraction and analysis}

A stepwise analysis on study design, aim of study, level of evidence, journal, number of procedures included in the study, prosthetic implant used, indication to TKA, mean age, body mass index (BMI), follow-up, and patellar resurfacing. Disparities in data extraction were discussed and resolved by consensus meeting between the authors. When studies reported mixed cohorts of patients, data extraction was selectively focused on procedures involving medial pivot implants.

Radiological data reported as pre- and post-operative femoral tibial angle (FTA), implant alignment with alpha angle $(\alpha)$, femoral beta angle $(\beta)$, sagittal femoral gamma angle $(\gamma)$, and sagittal tibial delta angle $(\delta)$ were collected. The femoral and tibial radiolucent lines (RLL) were also noted, and divided into major and progressive and minor and non-progressive, according to the knee society total knee arthroplasty roentgenographic evaluation and scoring system [17]. Continuous variables were expressed as weighted means and weighted standard deviation. Mean survivorship, clinical-functional outcomes, and radiographic angles were calculated as weighted means. All studies were assessed for revision for any reason. To evaluate survival rate of implants included in studies with different follow-up times, revisions per 100 components years (CY), which is a well-established method in orthopedic literature [18], were calculated. Studies missing data on the number of revisions performed were excluded from this analysis.

\section{Results}

The database research identified a total of 3655 studies. After initial screening, 191 studies were retrieved for full assessment. A total of 34 studies were included in the systematic review. Details are reported within Table 1. Two studies were level of evidence I [10, 19], 8 studies level II [9, 20-26], and 24 level IV [8, 11, 27-48].

The overall quality of the included study was very low according to GRADE system. Twenty-two studies were rated as very low quality $[8,11,27,28,30-45,47,48]$, 6 low quality [22-24, 26, 29, 46], 4 moderate [9, 10, 21, 25], and 2 high quality $[19,20]$ (Table 1). The risk of bias was considered high in 1 research [11], serious in 19 [8, 27, $30-36,38-45,47,48]$, and moderate in 4 [28, 29, 37, 46]; $9[9,19-26]$ had some concerns and one RCT [10] had low risk of bias.

A total of 3058 patients (3377 medial pivot design TKA) were finally included in this systematic review.

The mean age at surgery was $69.9 \pm 4.4$ years and the mean BMI was $29.9 \pm 1.0 \mathrm{~kg} / \mathrm{m}^{2}$. The mean follow-up was 85.8 months (range, 12-182). Patellar replacement was described in 23 studies [9-11, 20, 21, 23, 24, 26, 28, 30, 33, $35-40,42-46]$, and it was performed in $880(44.0 \%)$ cases on a total of 2000 procedures. 
Table 1 General characteristics of included studies

\begin{tabular}{|c|c|c|c|c|c|c|c|c|c|}
\hline Main author & Year & Study design & Patients $(n)$ & $\begin{array}{l}\text { TKA } \\
\text { procedure } \\
(n)\end{array}$ & $\begin{array}{l}\text { Mean age } \\
\text { (YEARS) }\end{array}$ & $\begin{array}{l}\text { Follow-up } \\
\text { (months) }\end{array}$ & Survivorship (\%) & $\begin{array}{l}\text { Risk of bias } \\
\text { (robins-I/Rob2) }\end{array}$ & $\begin{array}{l}\text { Level of } \\
\text { evidence } \\
\text { (CEBM) }\end{array}$ \\
\hline Mannan & 2009 & Prospective case series & 189 & 228 & - & 72 & 94.5 & Serious & IV \\
\hline Fan & 2010 & Retrospective case series & 56 & 58 & 65.1 & 64.7 & - & Serious & IV \\
\hline Hossain & 2011 & RCT & 40 & 40 & 72.5 & 24 & 100 & Low & $\mathrm{IIb}$ \\
\hline Vecchini & 2012 & Prospective case series & 160 & 172 & 71 & 84 & - & Moderate & IV \\
\hline Ishida & 2012 & $\mathrm{RCT}$ & 20 & 20 & 71 & 57 & - & Some concerns & $\mathrm{Ib}$ \\
\hline Brinkman & 2013 & Prospective case series & 47 & 50 & 69 & 119 & 98 & Serious & IV \\
\hline Youm & 2014 & Prospective case series & 80 & 120 & 66.4 & 64.7 & 99.9 & Serious & IV \\
\hline Chinzei & 2014 & Retrospective case series & 76 & 85 & 70.2 & 93.1 & - & Serious & IV \\
\hline Schmidt & 2014 & Prospective case series & 320 & 365 & 66.5 & 54 & 96.6 & Serious & IV \\
\hline Bae & 2015 & Prospective case-control & 125 & 150 & 66.7 & 63 & 98.6 & Serious & IV \\
\hline Katchky & 2016 & Prospective case series & 81 & 87 & 68 & 60 & 98 & Serious & IV \\
\hline Nakamura & 2016 & Retrospective case series & 51 & 70 & 82 & 142 & - & Serious & IV \\
\hline Choi & 2016 & Retrospective case-control & 28 & 49 & 66.7 & 64 & - & Serious & IV \\
\hline Karachalios & 2016 & Retrospective case series & 195 & 251 & 71 & 161 & 96.4 & Serious & IV \\
\hline Macheras & 2017 & Retrospective case series & 325 & 347 & 78 & 182 & 98.8 & Serious & IV \\
\hline Dehl & 2017 & Retrospective case series & 48 & 50 & 66.5 & 114 & 93 & Serious & IV \\
\hline Kim & 2017 & RCT & 182 & 182 & 65.6 & 144 & 99 & Some concerns & $\mathrm{IIb}$ \\
\hline Benjamin & 2018 & $\mathrm{RCT}$ & 45 & 45 & 62.4 & 12 & 100 & Low & $\mathrm{Ib}$ \\
\hline Nakamura & 2018 & Retrospective case-control & 45 & 45 & 74.3 & 24 & 100 & Serious & IV \\
\hline Samy & 2018 & Prospective case series & 76 & 76 & 64.4 & 12 & 98.5 & Moderate & IV \\
\hline Kohei & 2018 & $\mathrm{RCT}$ & 33 & 33 & 73.8 & 24 & 100 & Some concerns & $\mathrm{IIb}$ \\
\hline Sabatini & 2018 & Retrospective case series & 10 & 10 & - & 12 & - & High & IV \\
\hline Karachalios & 2018 & Prospective case-control & $\begin{array}{l}54 * \\
54 * *\end{array}$ & $\begin{array}{l}54 * \\
54 * *\end{array}$ & $\begin{array}{l}63.2 * \\
63.8 * *\end{array}$ & $\begin{array}{l}79 * \\
79 *\end{array}$ & $\begin{array}{l}100 * \\
100 * *\end{array}$ & Serious & IV \\
\hline Cacciola & 2019 & Retrospective case series & 297 & 315 & 74 & 66,4 & 98.3 & Moderate & IV \\
\hline Indelli & 2019 & $\mathrm{RCT}$ & 50 & 50 & 67.3 & 24 & 100 & Some concerns & $\mathrm{IIb}$ \\
\hline Gill & 2019 & $\mathrm{RCT}$ & 35 & 35 & 68.8 & 24 & - & Some concerns & $\mathrm{IIb}$ \\
\hline French & 2019 & $\mathrm{RCT}$ & 46 & 46 & 69 & 13.1 & 100 & Some concerns & $\mathrm{IIb}$ \\
\hline Yuan & 2019 & Retrospective case-control & 49 & 49 & 69.43 & 60 & 100 & Moderate & IV \\
\hline Indelli & 2020 & Retrospective case-control & $\begin{array}{l}50^{\dagger} \\
50^{\dagger \dagger}\end{array}$ & $\begin{array}{l}50^{\dagger} \\
50^{\dagger \dagger}\end{array}$ & $\begin{array}{l}68.5^{\dagger} \\
67.3^{\dagger \dagger}\end{array}$ & $\begin{array}{l}24^{\dagger} \\
24^{\dagger \dagger}\end{array}$ & $\begin{array}{l}100^{\dagger} \\
98^{\dagger \dagger}\end{array}$ & Serious & IV \\
\hline Lee & 2020 & $\mathrm{RCT}$ & 23 & 23 & 70 & 12 & - & Some concerns & $\mathrm{IIb}$ \\
\hline Jones & 2020 & Prospective case-control & 30 & 30 & 69.6 & 13.2 & - & Serious & IV \\
\hline Risitano & 2020 & Prospective case-control & 15 & 15 & 73.5 & 12 & 100 & Serious & IV \\
\hline Edelstein & 2020 & RCT & 25 & 25 & 67 & 24 & - & Some concerns & $\mathrm{IIb}$ \\
\hline Jeremic & 2020 & Prospective case-control & $\begin{array}{l}24^{\mathrm{a}} \\
24^{\mathrm{b}}\end{array}$ & $\begin{array}{l}24^{\mathrm{a}} \\
24^{\mathrm{b}}\end{array}$ & $\begin{array}{l}70.7^{\mathrm{a}} \\
72.5^{\mathrm{b}}\end{array}$ & $\begin{array}{l}12^{\mathrm{a}} \\
12^{\mathrm{b}}\end{array}$ & $\begin{array}{l}100^{\mathrm{a}} \\
100^{\mathrm{b}}\end{array}$ & Serious & IV \\
\hline
\end{tabular}

RCT Randomized Controlled Studies, TKA Total Knee Arthroplasty

$*$ Cementless components cohort, $* *$ cemented component cohort, ${ }^{\dagger} \mathrm{J}$ curve design cohort, ${ }^{\dagger \dagger}$ single radius Design cohort, ${ }^{\mathrm{a}}$ kinematically aligned, ${ }^{b}$ mechanically aligned

\section{Survivorship and revision rate}

The revisions per $100 \mathrm{CY}$ were 0.19 , which correspond to a revision rate of $1.9 \%$ after 10 years (Table 2). The causes of revision were: 16 cases of periprosthetic joint infection (PJI), 9 cases of aseptic loosening, 8 cases of periprosthetic fractures, 6 cases of persistent pain, 3 component failures (at least one TKA component), and 2 instabilities. Seven of the included studies did not report appropriate data on revisions rate, and then, these studies were not included in the calculation of overall revisions per $100 \mathrm{CY}$.

\section{Functional outcomes}

The pre-operative mean ROM was $103.4 \pm 1.5$ (CI 95\% 103.3-103.5 ${ }^{\circ}$. Mean pre-operative KSS and KSS for function were $38.7 \pm 1.7$ (CI 95\% 38.6-38.9) points and $45.8 \pm 4.4$ (CI 95\% 45.7-45.9) points, respectively, and 
Table 2 Revisions per 100 observed components years of the included studies

\begin{tabular}{|c|c|c|c|c|c|}
\hline Main author & $\begin{array}{l}\text { Follow- } \\
\text { up (year) }\end{array}$ & $\begin{array}{l}\text { Number of } \\
\text { procedures }\end{array}$ & $\mathrm{CY}$ & $\begin{array}{l}\text { Number of } \\
\text { revisions }\end{array}$ & $\begin{array}{l}100 \\
\text { Revi- } \\
\text { sion/CY }\end{array}$ \\
\hline Mannan & 6 & 228 & 1368 & 11 & 0.80 \\
\hline Fan & 5.4 & 58 & 313.2 & 0 & 0 \\
\hline Hossain & 2 & 40 & 80 & 0 & 0 \\
\hline Vecchini & 7 & 172 & 1204 & 2 & 0.17 \\
\hline Ishida & 4.8 & 20 & 96 & 0 & 0 \\
\hline Brinkman & 9.9 & 50 & 495 & 1 & 0.20 \\
\hline Youm & 5.4 & 120 & 648 & 1 & 0.15 \\
\hline Chinzei & 7.8 & 85 & 663 & 1 & 0.15 \\
\hline Schmidt & 4.5 & 365 & 1642.5 & 7 & 0.43 \\
\hline Bae & 5.3 & 150 & 795 & 2 & 0.25 \\
\hline Katchky & 5 & 87 & 435 & 2 & 0.46 \\
\hline Nakamura & 11.8 & 70 & 826 & 1 & 0.12 \\
\hline Choi & 5.3 & 49 & 259.7 & NA & NA \\
\hline Karachalios & 13.4 & 251 & 3363.4 & 6 & 0.18 \\
\hline Macheras & 15.2 & 347 & 5274.4 & 4 & 0.08 \\
\hline Dehl & 9.5 & 50 & 475 & 3 & 0.63 \\
\hline Kim & 12 & 182 & 2184 & 1 & 0.05 \\
\hline Benjamin & 1 & 45 & 45 & NA & NA \\
\hline Nakamura & 2 & 45 & 90 & 0 & 0 \\
\hline Samy & 1 & 76 & 76 & 0 & 0 \\
\hline Kohei & 2 & 33 & 66 & NA & NA \\
\hline Sabatini & 1 & 10 & 10 & 0 & 0 \\
\hline Karachalios & 6.6 & 108 & 712.8 & 0 & 0 \\
\hline Cacciola & 5.5 & 315 & 1732.5 & 2 & 0.12 \\
\hline Indelli & 2 & 50 & 100 & 0 & 0 \\
\hline Gill & 2 & 35 & 70 & NA & NA \\
\hline French & 1.1 & 46 & 50.6 & 0 & 0 \\
\hline Yuan & 5 & 49 & 245 & 0 & 0 \\
\hline Indelli & 2 & 100 & 200 & 0 & 0 \\
\hline Lee & 1 & 23 & 23 & NA & NA \\
\hline Jones & 1.1 & 30 & 33 & NA & NA \\
\hline Risitano & 1 & 15 & 15 & 0 & 0 \\
\hline Edelstein & 2 & 25 & 50 & NA & NA \\
\hline Jeremic & 1 & 48 & 48 & 0 & 0 \\
\hline
\end{tabular}

$C Y$ components years, $N A$ not available, $y$ years

mean pre-operative OKS was $38.6 \pm 8.6$ (CI 95\% 38.2-39.0) points. Considering post-operative results, mean ROM was $117.3 \pm 0.4^{\circ}$ (CI 95\% 117.29-117.31), clinical and functional KSS were $85.9 \pm 1.1$ (CI 95\% 85.88-85.92), and $84.7 \pm 3.6$ (CI 95\% 84.6-84.8). WOMAC and KOOS values were $39.1 \pm 7.6$ (CI 95\% 38.8-39.4) and 84.9 \pm 2.2 (CI 95\% 84.6-85.2), OKS was $28.2 \pm 5.7$ (CI 95\% 27.9-28.5), and FJS mean value was $68.5 \pm 1.0$ (CI 95\% 68.4-68.6).

Mean ROM of RCTs improved from $112.2 \pm 7.2^{\circ}$ (CI 95\%111.5-112.9) preoperatively to $115.9 \pm 1.6^{\circ}$ (CI 95\% 115.7-116.1) at final follow-up, while clinical and functional
KSS varied from $34.0 \pm 5.1$ (CI 95\% 33.3-34.7) and $44.7 \pm 0.2$ (CI 95\% 44.6-44.8) before surgery to $87.7 \pm 1.0$ (CI 95\% 87.6-87.8) and 78.1 \pm 2.6 (CI 95\% 77.8-78.4). OKS improved from $25.9 \pm 0.9$ (CI 95\% 25.7-26.1) to $35.9 \pm 1.5$ (CI 95\% 35.7-36.1).

Detailed functional outcomes are reported within Table 3.

\section{Radiographic outcomes}

Eight studies [19, 23, 27, 35, 39, 41, 43, 48] reported a preoperative varus deformity (699 TKA [47.4\%], mean FTA value: $186.9 \pm 0.4^{\circ}$ [CI 95\% 186.8-187.0]), and other 6 $[9,21,29,36,38,44]$ reported a valgus FTA (774 TKA [52.6\%], mean FTA $174.6 \pm 0.3^{\circ}$ [CI 95\% 174.5-174.7]). The overall pre-operative FTA was $180.5 \pm 0.8^{\circ}$. Mean postoperative FTA after 6.9 years was $177.1 \pm 0.1^{\circ}$ (CI 95\% 177.0-177.2). Post-operative alfa and beta knee angles mean values after 8,4 years were $95.6 \pm 0.4^{\circ}$ (CI 95\% 95.5-95.7) and $89.1 \pm 0.2^{\circ}$ (CI 95\% 89.0-89.2), respectively, while the gamma and delta angles and their mean values were $2.3 \pm 0.7^{\circ}(\mathrm{CI} 95 \% 2.2-2.4)$ after 8.4 years and $86.7 \pm 0.4^{\circ}$ (CI 95\% 86.6-86.8) after 8.7 years.

Minor $(<2 \mathrm{~mm})$ and non-progressive femoral radiolucent lines were found in $146(7.5 \%)$ knees on the femoral side and in $175(9.0 \%)$ cases on the tibial side. Major or progressive femoral RLL were reported in $11(0.5 \%)$ cases. Two studies $[8,35]$ reported $12(0.6 \%)$ RLL minor case without mentioning the exact localization.

Post-operative outliers were 116 (24.3\%) cases (mechanical axis alignment \pm 3 degrees). Regarding RCTs, the FTA varied from $188.1 \pm 5.7^{\circ}$ (CI 95\% 187.4-188.8) after the procedure to $175.9 \pm 2.3^{\circ}$ (CI 95\% 175.2-176.6) after 9.1 years.

Post-operative alfa and beta angles were $96.6 \pm 2.2^{\circ}$ (CI 95\% 96.3-96.9) and $88.6 \pm 0.1^{\circ}$ (CI 95\% 88.5-88.7), while gamma and delta values were $2.8 \pm 0.4^{\circ}$ (CI 95\% 2.7-2.9) and $86.5 \pm 0.5^{\circ}$ (CI 95\% 86.4-86.6). In RCT, studies were not reported any case of RLL or AL. Details of radiological measurements are reported within Table 4.

\section{Complications}

The main complications were $30(1.0 \%)$ cases of stiffness, $25(0.9 \%)$ cases of deep vein thrombosis, $17(0.6 \%)$ PJIs, $17(0.6 \%)$ superficial wound infections, $16(0.6 \%)$ cases of persistent pain, $16(0.6 \%)$ retarded wound healings, and 11 $(0.4 \%)$ periprosthetic fractures.

Other reported complications were $7(0.2 \%)$ cases of pulmonary thromboembolism, $6(0.2 \%)$ AL, $6(0.2 \%)$ peroneal neurapraxias, $4(0.1 \%)$ cases of persistent knee swelling, 3 $(0.1 \%)$ cases of patellar fractures, $3(0.1 \%)$ cases of knee instability, 1 regional pain syndrome, and 1 patellar tendon rupture. In RCT studies, 14 (3\%) cases of stiffness and 4 PJI were reported. Of these, three patients needed reoperation. 


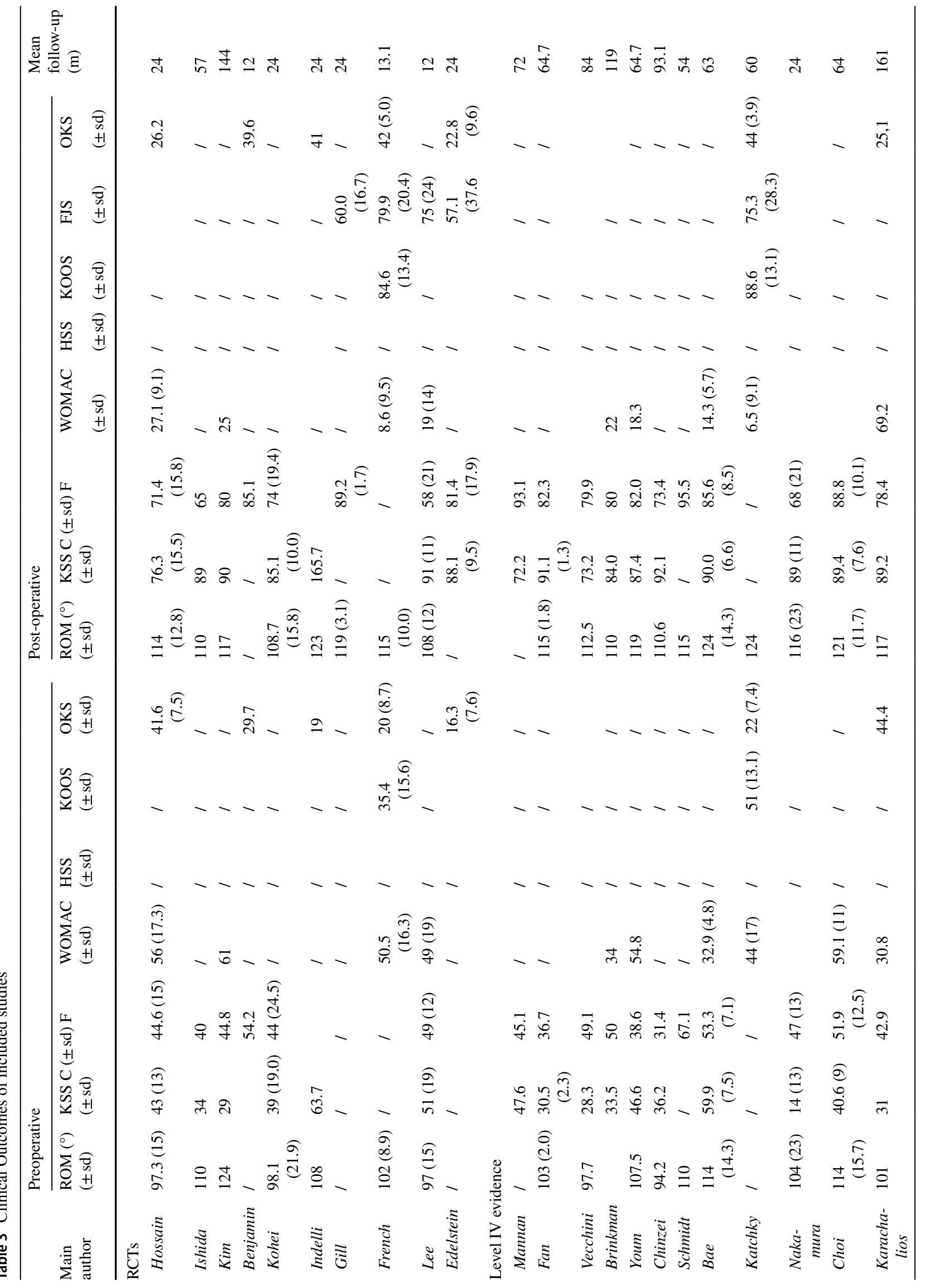




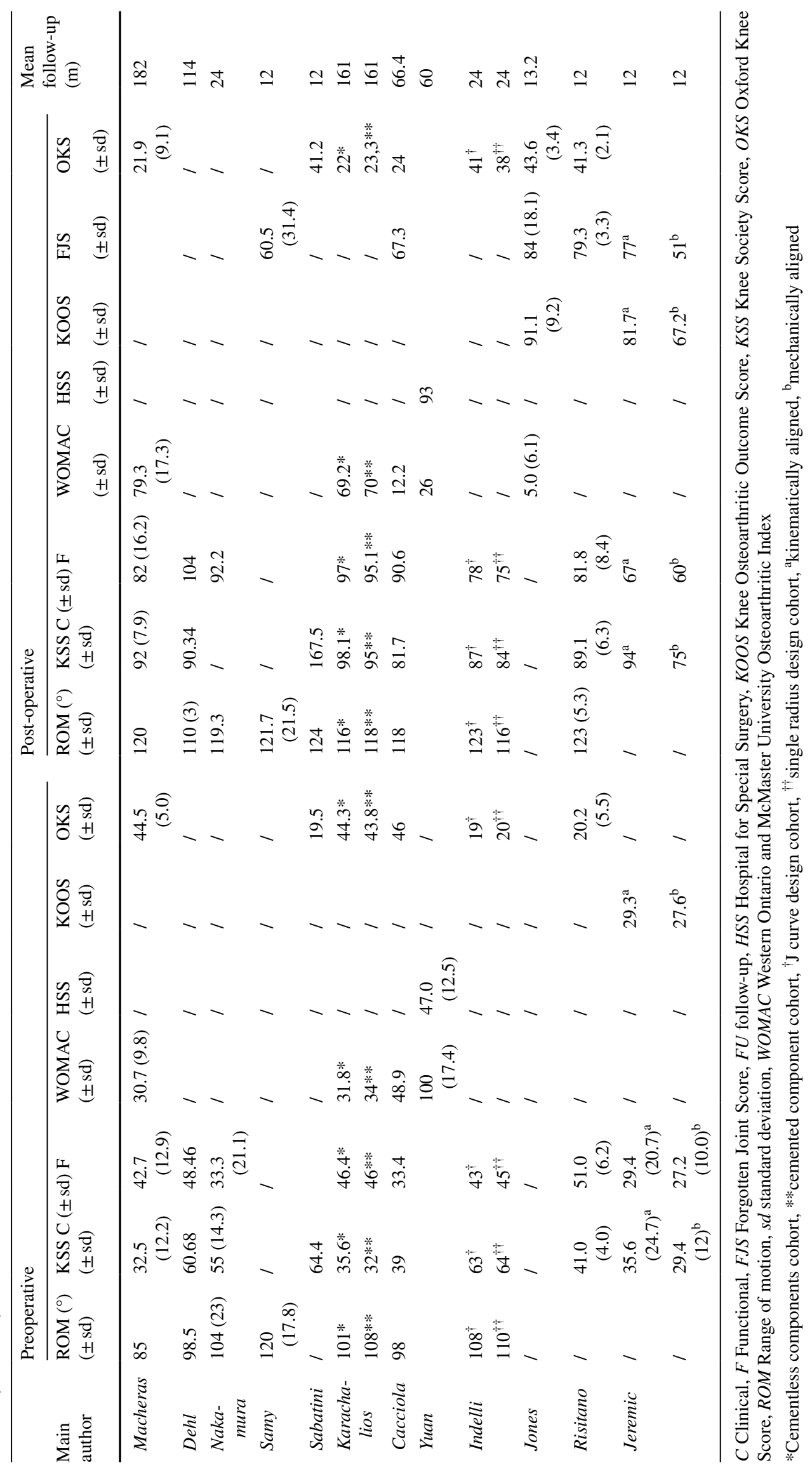


Table 4 Radiographic outcomes of included studies

\begin{tabular}{|c|c|c|c|c|c|c|}
\hline \multirow[t]{2}{*}{ Main author } & \multirow{2}{*}{$\begin{array}{l}\text { Preoperative } \\
\text { FTA }\left(^{\circ}\right),( \pm \mathrm{sd})\end{array}$} & \multicolumn{5}{|l|}{ Post-operative } \\
\hline & & Alfa $\left(^{\circ}\right)( \pm$ sd $)$ & Beta $\left(^{\circ}\right)( \pm s d)$ & $\operatorname{Gamma}\left(\left(^{\circ}\right)( \pm \mathrm{sd})\right.$ & Delta $\left(^{\circ}\right)( \pm$ sd $)$ & FTA $\left({ }^{\circ}\right)( \pm \mathrm{sd})$ \\
\hline \multicolumn{7}{|l|}{ RCTs } \\
\hline Kohei & Valgus 9 (4.1) & $89.4(1.7)$ & $89.1(2.1)$ & $4.6(2.8)$ & $86.3(3.1)$ & Varus $1(2.3)$ \\
\hline Hossain & Valgus 4.0 (4.3) & $95.6(3.9)$ & $88.4(1.9)$ & $2.4(2.7)$ & $88.7(4.3)$ & l \\
\hline Ishida & Varus 12 & I & I & l & & Varus 1 \\
\hline Kim & Varus 10.8 & 98.1 & 88.6 & 2.5 & 86.1 & Valgus 5.6 \\
\hline Nakamura & $181.3(5.2)$ & 100 & 88.1 & 6.2 & 87.8 & 174.2 \\
\hline Cacciola & 4.5 valgus & 96.8 & 88.4 & 1.6 & 88.7 & Varus 2.8 \\
\hline Sabatini & I & I & I & l & l & Valgus 4 \\
\hline \multirow[t]{2}{*}{ Indelli } & I & I & I & l & 84 & Valgus 4.2 \\
\hline & I & l & / & l & 87 & Valgus 4.2 \\
\hline Katchky & I & l & I & l & l & Varus $2^{\circ}$ \\
\hline Choi & Varus $5.9(4.0)$ & $97.1(3.4)$ & $89.9(1.5)$ & $4.5(3.6)$ & $85(1.1)$ & Valgus 5.6 \\
\hline \multicolumn{7}{|c|}{ Level IV evidence } \\
\hline Mannan & Valgus 6.4 & 96.6 & 89 & 3.4 & 88.3 & Valgus 5.6 \\
\hline Vecchini & I & 88.2 & 94 & l & l & l \\
\hline Dehl & 175 & 96.8 & 87.6 & 5.8 & 86 & 179 \\
\hline Youm & Varus $4.6(4.5)$ & $96.2(2.1)$ & $89.1(1.7)$ & $2.5(1.5)$ & $84.4(2.7)$ & Valgus 5.8 (2.4) \\
\hline Chinzei & 10.7 & I & I & l & l & 1.4 \\
\hline Bae & Varus 4.1 & 95.3 & 90.1 & 3.0 & 84.8 & Valgus 5.6 \\
\hline \multirow[t]{2}{*}{ Karachalios } & Valgus 5 & 97 & 88.5 & 1 & 85 & Valgus 4.7 \\
\hline & Valgus 5.2 & 97 & 89 & 1 & 85 & Valgus 4.8 \\
\hline Macheras & / & 95 & 88.5 & 1 & 87.5 & I \\
\hline Karachalios & I & 97 & 88.5 & 1 & 85.5 & Valgus 4.5 \\
\hline Risitano & I & l & I & l & I & Varus 1.8 \\
\hline \multirow[t]{2}{*}{ Jeremic } & Varus $4.9^{\mathrm{a}}$ & $91.5^{\mathrm{a}}$ & $88.4^{\mathrm{a}}$ & l & l & Varus $0.2^{\mathrm{a}}$ \\
\hline & Varus $5.2^{\mathrm{b}}$ & $90.1^{\mathrm{b}}$ & $89.0^{\mathrm{b}}$ & I & / & Varus $0.15^{\mathrm{b}}$ \\
\hline
\end{tabular}

FTA Femoral-tibial angle, $s d$ standard deviation

${ }^{\mathrm{a}}$ kinematically aligned, ${ }^{\mathrm{b}}$ mechanically aligned

\section{Discussion}

The aim of this systematic review was to summarize the literature evidence on survivorship and clinical-radiological outcomes of the medial pivoting design TKA. To the best of our knowledge, this is the first systematic review of the literature with a detailed ROM report, patient-reported and objective outcome measures, radiological outcomes, and complications of patients who underwent medial pivot TKA.

Although knee replacement is one of the most performed surgical procedures worldwide, some concerns are related to the relatively high percentage of unsatisfactory outcomes $[49,50]$. Native knee kinematics is complex and consists of a constrained pivoting medial compartment and a lateral femoral condyle which can slide posteriorly at high grades of flexion [51, 52]. Medial pivoting designs have been proposed to mimic native knee kinematic and potentially improve clinical outcomes of classic PS TKA designs.
The most important finding of this research is the excellent overall survivorship of medial pivoting design TKA. In fact, the revisions per $100 \mathrm{CY}$ were 0.19 , corresponding to a revision rate of $1.9 \%$ after 10 years (Fig. 2). Only 51 revision TKA procedures were reported in the literature included in the current review. However, despite the overall excellent survivorship of these implants, survival analysis showed some outliers, as represented in Fig. 2 [8, 36, 38]. In particular, the mean survivorship reported in the retrospective study by Dehl et al. [38] was $93.0 \%$ at the final 9.5 year follow-up which is lower than the median value of the overall population studied. However, it should be considered that the small sample size of this study could have overestimated the revision rate, which main causes were not related to the implant design, such as arthrofibrosis and infections. Moreover, it should be highlighted that median values are not significantly affected by the presence of outliers. Some values points reported in the scatterplot (Fig. 2) are outside the 95\% CI, showing the quite large dispersion of values around 
Fig. 2 Scatterplot representing the relationship between survivorship and follow-up in each study included in the review. Solid line, linear median value of survivorship at different follow-up times. Dotted line, 95\% CI of median survivorship calculated with the Wilcoxon $t$ test

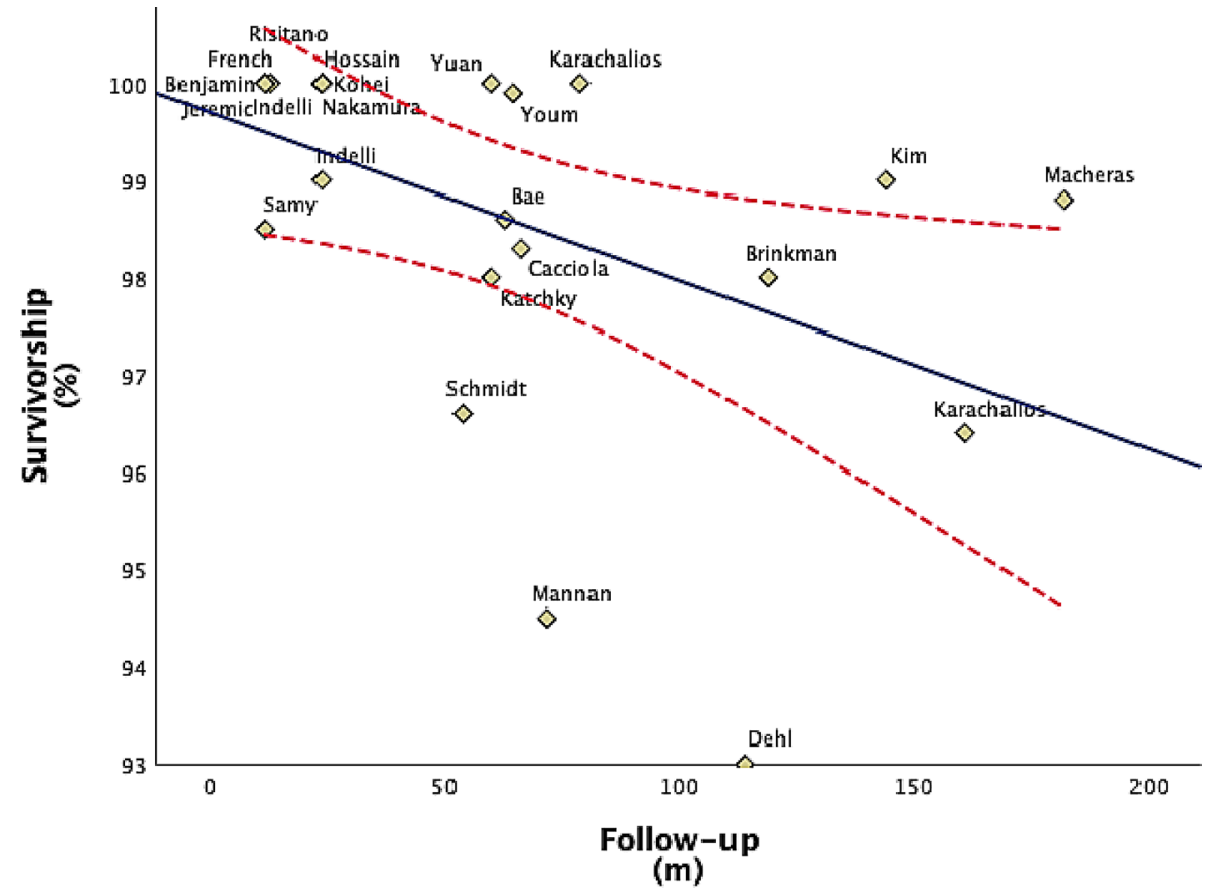

the line representing the projected median; then, any further conclusion based on the data presented in this review should be weighted considering this evidence. Nevertheless, it must be reminded that the $95 \% \mathrm{CI}$ is a tool to assess the method to esteem values; then, real values should not be expected to be included into the interval.

Furthermore, medial pivot TKA showed good-to-excellent results in term of objective and patient-reported outcomes measures (Table 3). The RCTs included in this review demonstrated good-to-excellent clinical results of the medial pivot TKA, with strong improvement of KSS (from 34.0 to 87.7) and slight increase of ROM (from $112^{\circ}$ to $115^{\circ}$ ). However, we point out that on a total of 9 RCTs included, only three studies demonstrated that the medial pivoting TKA had a better clinical results when compared to other knee implants (posterior stabilized and cruciate retaining) [9, 24, 25]. French et al. [25] reported significantly better FJS and quality of life subscale of the KOOS and KOOS12 in a subgroup of patients who had undergone medial pivot TKA compared to cruciate retaining TKA. However, other patient-reported outcomes and ROM were comparable between the groups. Gill et al. [24] found better results in the group treated with medial pivot implants demonstrating better KSS, ROM, and FJS. On the contrary, Kim et al. [23] observed higher complication rates and worse knee scores, ROM, and patient satisfaction in the medial pivot design group than in the cruciate retaining group. Jeremic et al. [48] reported higher 1 year performance of kinematically medial pivot TKA compared to mechanically aligned ones.

A potential conflict of interest was disclosed in ten studies $[9,10,21,25,28,38,42,44,45,48]$ where authors reported receipt of payment, either direct or indirect, institutional support, and association with a biomedical field entity related to the medial pivot TKA, raising some concerns and precluding the reliable interpretation of clinical results.

Hossain et al. [9] found better ROM in the medial pivot TKA than in the posterior stabilized design $\left(114.9^{\circ}\right.$ vs $100.1^{\circ}$ ). Moreover, physical component scores of SF-36 and Total Knee Function Questionnaire were better in the medial conforming ball-and-socket group. However, no differences were found in the American Knee Society, WOMAC, and Oxford Knee scores. Benjamin et al. [10] performed a gait analysis comparing the medial pivot TKA with the single radius PS implant. They found no significant differences in cadence, walking speed, stride length and stance time, peak stride, mid-support, and push-off forces.

This study has several limitations. First, there is a low level of evidence among included studies, since 22 papers were classified as level of evidence IV. Moreover, only one research was considered at low risk of bias precluding strong conclusions on the results of the included studies. No quality restriction was applied to obtain the largest population of medial pivot TKA. There are possible selection biases deriving from different diagnosis and high heterogeneity in TKA indications that include population (i.e., comorbidities, age, and pre-operative level of activity).

Heterogeneous RCTs studies have been included where the medial pivoting design was compared to the conventional posterior stabilized and cruciate retaining TKA or compared to other models of the medial pivot TKA. All reported outcome measures were highly heterogeneous resulting in a difficult systematic analysis. To reduce bias, the largest number 
of procedures available in the literature were included and variables gathered from RCTs were analyzed separately.

Conflict of interests were disclosed in several included studies, and this aspect can overestimate the medial pivot TKA outcomes. Only six studies [23, 33, 34, 38, 42, 45] reported survivorship and complications over 10 years raising some concerns of long-term failure risk of the medial pivot TKA.

\section{Conclusions}

Medial pivoting design TKAs provided high survivorship of implants, with a revision rate of $1.9 \%$ after 10 years. Moreover, good-to-excellent results were obtained in term of objective and patient-reported outcomes measures. Radiological evaluation of studies showed excellent post-operative correction of axial deformities. Three RCTs demonstrated better functional outcomes of medial pivoting designs when compared to the conventional TKA. Only one RCT showed worse results in the medial pivoting group, whereas the remaining RCTs demonstrated non-significant differences between groups. However, several limitations and biases affect this review and further high-quality studies are needed to clarify the role of medial pivoting implants in TKA.

Supplementary Information The online version contains supplementary material available at https://doi.org/10.1007/s00402-021-04210-6.

Funding Open access funding provided by Università degli Studi di Genova within the CRUI-CARE Agreement. There is no funding source.

\section{Declarations}

Conflict of interest The authors declare that they have no conflict of interest.

Ethical approval This article does not contain any studies with human participants or animals performed by any of the authors.

Open Access This article is licensed under a Creative Commons Attribution 4.0 International License, which permits use, sharing, adaptation, distribution and reproduction in any medium or format, as long as you give appropriate credit to the original author(s) and the source, provide a link to the Creative Commons licence, and indicate if changes were made. The images or other third party material in this article are included in the article's Creative Commons licence, unless indicated otherwise in a credit line to the material. If material is not included in the article's Creative Commons licence and your intended use is not permitted by statutory regulation or exceeds the permitted use, you will need to obtain permission directly from the copyright holder. To view a copy of this licence, visit http://creativecommons.org/licenses/by/4.0/.

\section{References}

1. Flierl MA, Sobh AH, Culp BM et al (2019) Evaluation of the painful total knee arthroplasty. J Am Acad Orthop Surg 27(20):743-751

2. Kurtz S, Ong K, Lau E et al (2007) Projections of primary and revision hip and knee arthroplasty in the United States from 2005 to 2030. J Bone Jt Surg Ser A. https://doi.org/10.2106/JBJS.F. 00222

3. Inacio MCS, Paxton EW, Graves SE et al (2017) Projected increase in total knee arthroplasty in the United States-an alternative projection model. Osteoarthr Cartil. https://doi.org/10. 1016/j.joca.2017.07.022

4. Romanini E, Decarolis F, Luzi I et al (2019) Total knee arthroplasty in Italy: reflections from the last fifteen years and projections for the next thirty. Int Orthop. https://doi.org/10.1007/ s00264-018-4165-7

5. Hofmann S, Seitlinger G, Djahani O, Pietsch M (2011) The painful knee after TKA: a diagnostic algorithm for failure analysis. Knee Surg Sport Traumatol Arthrosc. https://doi.org/10.1007/ s00167-011-1634-6

6. Mugnai R, Digennaro V, Ensini A et al (2014) Can TKA design affect the clinical outcome? Comparison between two guidedmotion systems. Knee Surg Sport Traumatol Arthrosc. https:// doi.org/10.1007/s00167-013-2509-9

7. Freeman MAR, Pinskerova V (2005) The movement of the normal tibio-femoral joint. J Biomech. https://doi.org/10.1016/j.jbiomech. 2004.02.006

8. Schmidt R, Ogden S, Blaha JD et al (2014) Midterm clinical and radiographic results of the medial pivot total knee system. Int Orthop 38:2495-2498. https://doi.org/10.1007/ s00264-014-2444-5

9. Hossain F, Patel S, Rhee SJ, Haddad FS (2011) Knee arthroplasty with a medially conforming ball-and-socket tibiofemoral articulation provides better function. Clin Orthop Relat Res 469:55-63. https://doi.org/10.1007/s11999-010-1493-3

10. Benjamin B, Pietrzak JRT, Tahmassebi J, Haddad FS (2018) A functional comparison of medial pivot and condylar knee designs based on patient outcomes and parameters of gait. Bone Jt J 100B:76-82. https://doi.org/10.1302/0301-620X.100B1.BJJ2017-0605.R1

11. Sabatini L, Risitano S, Parisi G et al (2018) Medial pivot in total knee arthroplasty: literature review and our first experience. Clin Med Insights Arthritis Musculoskelet Disord 11:1-3. https://doi. org/10.1177/1179544117751431

12. Cumpston M, Li T, Page MJ et al (2019) Updated guidance for trusted systematic reviews: a new of the Cochrane Handbook for Systematic Reviews of Interventions. Cochrane Database Syst Rev 10:ED000142

13. Moher D, Liberati A, Tetzlaff J et al (2009) Preferred reporting items for systematic reviews and meta-analyses: the PRISMA statement. PLoS Med 6(7):e1000097

14. OLoEW G (2016) The Oxford levels of evidence 2. Oxford cent evidence-based med. https://www.cebm.net/index.aspx?o=5653

15. Guyatt GH, Oxman AD, Vist GE et al (2008) GRADE: an emerging consensus on rating quality of evidence and strength of recommendations. BMJ. https://doi.org/10.1136/bmj.39489.470347.ad

16. Sterne JA, Hernán MA, Reeves BC et al (2016) ROBINS-I: a tool for assessing risk of bias in non-randomised studies of interventions. BMJ. https://doi.org/10.1136/bmj.i4919

17. Caplan N, Kader DF (2014) The knee society total knee arthroplasty roentgenographic evaluation and scoring system. Classic papers in orthopaedics. Springer, London, pp 193-195

18. Hauer G, Bernhardt GA, Hohenberger G et al (2020) Similar revision rates in clinical studies and arthroplasty registers and no bias 
for developer publications in unicompartmental knee arthroplasty. Arch Orthop Trauma Surg 140:537-544. https://doi.org/10.1007/ s00402-020-03336-3

19. Ishida K, Matsumoto T, Tsumura $\mathrm{N}$ et al (2014) No difference between double-high insert and medial-pivot insert in TKA. Knee Surg Sport Traumatol Arthrosc 22:576-580. https://doi.org/10. 1007/s00167-012-2314-x

20. Indelli PF, Risitano S, Hall KE et al (2019) Effect of polyethylene conformity on total knee arthroplasty early clinical outcomes. Knee Surg Sport Traumatol Arthrosc 27:1028-1034. https://doi. org/10.1007/s00167-018-5170-5

21. Nishitani K, Furu M, Nakamura S et al (2018) No differences in patient-reported outcomes between medial pivot insert and symmetrical insert in total knee arthroplasty: a randomized analysis. Knee 25:1254-1261. https://doi.org/10.1016/j.knee.2018.08.005

22. Lee QJ, Wai Yee EC, Wong YC (2020) No difference in patient preference for medial pivot versus posterior-stabilized design in staged bilateral total knee arthroplasty: a prospective study. Knee Surg Sport Traumatol Arthrosc. https://doi.org/10.1007/ s00167-020-05867-z

23. Kim YH, Park JW, Kim JS (2017) Clinical outcome of medial pivot compared with press-fit condylar sigma cruciate-retaining mobile-bearing total knee arthroplasty. J Arthroplast 32:30163023. https://doi.org/10.1016/j.arth.2017.05.022

24. Gill UN, Shiraz HM, Rehman MKU et al (2019) Comparison of functional outcome of medial pivot total knee arthroplasty with posterior stabilizing (PS) total knee arthroplasty—a randomized trial. Pak J Med Health Sci 13:385-388

25. French SR, Munir S, Brighton R (2020) A single surgeon series comparing the outcomes of a cruciate retaining and medially stabilized total knee arthroplasty using kinematic alignment principles. J Arthroplast 35:422-428. https://doi.org/10.1016/j.arth. 2019.09.021

26. Edelstein AI, Bhatt S, Wright-Chisem J et al (2020) The effect of implant design on sagittal plane stability: a randomized trial of medial-versus posterior-stabilized total knee arthroplasty. J Knee Surg. https://doi.org/10.1055/s-0039-1678524

27. Nakamura J, Inoue T, Suguro T et al (2018) A comparative study of flat surface design and medial pivot design in posterior cruciate-retaining total knee arthroplasty: a matched pair cohort study of two years. BMC Musculoskelet Disord 19:1-7. https://doi.org/ 10.1186/s12891-018-2138-z

28. Samy DA, Wolfstadt JI, Vaidee I, Backstein DJ (2018) A retrospective comparison of a medial pivot and posterior-stabilized total knee arthroplasty with respect to patient-reported and radiographic outcomes. J Arthroplast 33:1379-1383. https://doi.org/10. 1016/j.arth.2017.11.049

29. Cacciola G, De Martino I, De Meo F (2020) Does the medial pivot knee improve the clinical and radiographic outcome of total knee arthroplasty? A single centre study on two hundred and ninety seven patients. Int Orthop 44:291-299. https://doi.org/10.1007/ s00264-019-04462-3

30. Indelli PF, Morello F, Ghirardelli S et al (2020) No clinical differences at the 2-year follow-up between single radius and J-curve medial pivot total knee arthroplasty in the treatment of neutral or varus knees. Knee Surg Sport Traumatol Arthrosc. https://doi.org/ 10.1007/s00167-020-05854-4

31. Jones CW, Jacobs H, Shumborski S et al (2020) Sagittal stability and implant design affect patient reported outcomes after total knee arthroplasty. J Arthroplast 35:747-751. https://doi.org/10. 1016/j.arth.2019.10.020

32. Katchky AM, Jones CW, Walter WL, Shimmin AJ (2019) Medial ball and socket total knee arthroplasty. Bone Jt J 101-B:59-65. https://doi.org/10.1302/0301-620x.101b1.bjj-2018-0434.r1
33. Macheras GA, Galanakos SP, Lepetsos P et al (2017) A long term clinical outcome of the medial pivot knee arthroplasty system. Knee 24:447-453. https://doi.org/10.1016/j.knee.2017.01.008

34. Nakamura S, Minoda Y, Nakagawa S et al (2017) Clinical results of alumina medial pivot total knee arthroplasty at a minimum follow-up of 10 years. Knee. https://doi.org/10.1016/j.knee.2016. 12.011

35. Choi NY, In Y, Bae JH et al (2017) Are midterm patient-reported outcome measures between rotating-platform mobile-bearing prosthesis and medial-pivot prosthesis different? A minimum of 5-year follow-up study. J Arthroplast 32:824-829. https://doi.org/ 10.1016/j.arth.2016.08.028

36. Mannan K, Scott G (2009) The Medial Rotation total knee replacement: a clinical and radiological review at a mean followup of six years. J Bone Jt Surg Ser B 91:750-756. https://doi. org/10.1302/0301-620X.91B6.22124

37. Vecchini E, Christodoulidis A, Magnan B et al (2012) Clinical and radiologic outcomes of total knee arthroplasty using the advance medial pivot prosthesis. a mean 7 years follow-up. Knee 19:851855. https://doi.org/10.1016/j.knee.2012.04.002

38. Dehl M, Bulaïd Y, Chelli M et al (2018) Total knee arthroplasty with the medial-pivot knee system: clinical and radiological outcomes at 9.5 years' mean follow-up. Orthop Traumatol Surg Res 104:185-191. https://doi.org/10.1016/j.otsr.2017.10.016

39. Youm Y-S, Cho S-D, Lee S-H, Cho H-Y (2014) Total knee arthroplasty using a posterior cruciate ligament sacrificing medial pivot knee: minimum 5-year follow-up results. Knee Surg Relat Res 26:135-140. https://doi.org/10.5792/ksrr.2014.26.3.135

40. Fan CY, Hsieh JTS, Hsieh MS et al (2010) Primitive results after medial-pivot knee arthroplasties. A minimum 5-year follow-up study. J Arthroplast 25:492-496. https://doi.org/10.1016/j.arth. 2009.05.008

41. Chinzei N, Ishida K, Tsumura N et al (2014) Satisfactory results at 8 years mean follow-up after ADVANCE® medial-pivot total knee arthroplasty. Knee 21:387-390. https://doi.org/10.1016/j. knee.2013.10.005

42. Brinkman JM, Bubra PS, Walker P et al (2014) Midterm results using a medial pivot total knee replacement compared with the Australian National Joint Replacement Registry data. ANZ J Surg. https://doi.org/10.1111/ans. 12428

43. Bae DK, Do CS, Im SK, Song SJ (2016) Comparison of midterm clinical and radiographic results between total knee arthroplasties using medial pivot and posterior-stabilized prosthesis-matched pair analysis. J Arthroplast 31:419-424. https://doi.org/10.1016/j. arth.2015.09.038

44. Karachalios T, Komnos G, Amprazis V et al (2018) A 9-year outcome study comparing cancellous titanium-coated cementless to cemented tibial components of a single knee arthroplasty design. J Arthroplast 33:3672-3677. https://doi.org/10.1016/j.arth.2018. 07.014

45. Karachalios T, Varitimidis S, Bargiotas K et al (2016) An 11- to 15-year clinical outcome study of the advance medial pivot total knee arthroplasty: pivot knee arthroplasty. Bone Jt J 98-B:1050 1055. https://doi.org/10.1302/0301-620X.98B8.36208

46. Yuan D, Zhang Q-S, Zhang K et al (2019) Total knee arthroplasty using a medial pivot or posterior cruciate-stabilizing prosthesis in Chinese patients. J Knee Surg. https://doi.org/10.1055/s-00391688784

47. Risitano S, Sabatini L, Barberis L et al (2020) Combining kinematic alignment and medial stabilized design in total knee arthroplasty: basic rationale and preliminary clinical evidences. $\mathrm{J}$ Orthop. https://doi.org/10.1016/j.jor.2020.08.025

48. Jeremić DV, Massouh WM, Sivaloganathan S et al (2020) Shortterm follow-up of kinematically vs mechanically aligned total knee arthroplasty with medial pivot components: a case-control 
study. Orthop Traumatol Surg Res. https://doi.org/10.1016/j.otsr. 2020.04.005

49. Milner CE (2009) Is gait normal after total knee arthroplasty? Systematic review of the literature. J Orthop Sci 14(1):114-120

50. Wylde V, Dieppe P, Hewlett S, Learmonth ID (2007) Total knee replacement: Is it really an effective procedure for all? Knee 14(6):417-423

51. Pinskerova V, Johal P, Nakagawa $S$ et al (2004) Does the femur roll-back with flexion? J Bone Jt Surg Ser B. https://doi.org/10. 1302/0301-620X.86B6.14589
52. van Duren BH, Pandit H, Beard DJ et al (2007) How effective are added constraints in improving TKR kinematics? J Biomech. https://doi.org/10.1016/j.jbiomech.2007.02.016

Publisher's Note Springer Nature remains neutral with regard to jurisdictional claims in published maps and institutional affiliations. 